\title{
Low-Dose Methylmercury-Induced Apoptosis and Mitochondrial DNA Mutation in Human Embryonic Neural Progenitor Cells
}

\author{
Xinjin Wang, Mengling Yan, Lina Zhao, Qing Wu, Chunhua Wu, \\ Xiuli Chang, and Zhijun Zhou \\ School of Public Health/Key Laboratory of Public Health Safety of Ministry of Education/WHO Collaborating Center for Occupational \\ Health/Collaborative Innovation Center of Social Risks Governance in Health, Fudan University, Shanghai 200032, China
}

Correspondence should be addressed to Xiuli Chang; xlchang@fudan.edu.cn

Received 4 April 2016; Revised 6 June 2016; Accepted 22 June 2016

Academic Editor: Marcos R. de Oliveira

Copyright ( 2016 Xinjin Wang et al. This is an open access article distributed under the Creative Commons Attribution License, which permits unrestricted use, distribution, and reproduction in any medium, provided the original work is properly cited.

Methylmercury $(\mathrm{MeHg})$ is a long-lasting organic pollutant primarily found in the aquatic environment. The developing brain is particularly sensitive to $\mathrm{MeHg}$ due to reduced proliferation of neural stem cell. Although several mechanisms of $\mathrm{MeHg}$ induced apoptosis have been defined in culture models, it remains unclear whether mitochondrial DNA (mtDNA) mutation is involved in the toxic effect of $\mathrm{MeHg}$, especially in the neural progenitor cells. In the present study, the ReNcell CX cell, a human neural progenitor cells (hNPCs) line, was exposed to nanomolar concentrations of $\mathrm{MeHg}(\leq 50 \mathrm{nM})$. We found that MeHg altered mitochondrial metabolic function and induced apoptosis. In addition, we observed that MeHg induced ROS production in a dose-dependent manner in hNPCs cells, which was associated with significantly increased expressions of ND1, Cytb, and ATP6. To elucidate the mechanism underlying MeHg toxicity on mitochondrial function, we examined the ATP content and mitochondrial membrane potential in MeHg-treated hNPCs. Our study showed that MeHg exposure led to decreased ATP content and reduced mitochondrial membrane potential, which failed to match the expansion in mtDNA copy number, suggesting impaired mtDNA. Collectively, these results demonstrated that $\mathrm{MeHg}$ induced toxicity in hNPCs through altering mitochondrial function and inducing oxidative damage to mtDNA.

\section{Introduction}

Methylmercury $(\mathrm{MeHg})$ is a long-lasting organic pollutant primarily found in the aquatic environment. Due to the biomethylation of inorganic mercury released from anthropogenic sources in waterways, $\mathrm{MeHg}$-contaminated seafood is a major source of human exposure [1]. Therefore, residents that depend heavily on fish for food can be exposed to toxic levels of $\mathrm{MeHg}$ [2]. Although $\mathrm{MeHg}$ is distributed among various tissues after absorption, brain is its main target, especially the developing central nervous system [3]. Some epidemiological studies have shown that motor and cognitive impairments are the most common neurological changes observed in these populations $[4,5]$. It is noteworthy that exposure to $\mathrm{MeHg}$ during early life period can be associated with subtle brain damage at levels much lower than those affecting the mature brain $[6,7] . \mathrm{MeHg}$ can elicit pivotal events including calcium homeostasis, mitochondrial dysfunction, formation of reactive oxygen species, and induction of cell death by apoptosis or necrosis through $\mathrm{MeHg}$-induced oxidative stress $[3,8]$. However, our understanding of the primary critical targets of $\mathrm{MeHg}$, namely, those which trigger $\mathrm{MeHg}$ neurotoxicity, remains incipient.

Although the underlying mechanisms of MeHg-induced neurotoxicity are not completely understood, several lines of evidence demonstrate that reactive oxygen species (ROS) generation in mitochondrial respiration chain (MRC) stress represents a critical event related to the neurotoxic effects caused by this toxicant. Some studies have consistently shown that $\mathrm{MeHg}$ exposure can cause oxidative damage in macromolecules, such as lipids and DNA [9]. Mitochondrial DNA (mtDNA) is considered more prone to oxidative damage and consequently gets mutations at a higher rate than does nuclear DNA (nDNA) $[10,11]$. This is because mtDNA are 
easily exposed to high levels of ROS generated during respiration [11]. Moreover, mtDNA lacks protective histones with limited capacity for repair of DNA damage [12]. In addition, mtDNA mutagenesis may be closely related to the stability of the organelle and to mitochondria related apoptosis signaling [11]. Indeed, it has been reported that more ROS are generated from mitochondria in ETC-inhibited and mtDNA-damaged cells [12].

In general, mitochondria produce ATP, act as biosensors for oxidative stress, and eventually become effector organelles for programmed cell death. MeHg can induce apoptosis via the classical mitochondrial pathway in neural stem cells which are in oxidative stress $[13,14]$. It is commonly believed that $\mathrm{MeHg}$ can also damage the mitochondrial membrane potential, interfere with the function of ETC, and influence the production of ATP by reacting with sulfhydryl groups, which are the components of the mitochondrial membrane protein. Alternations in mitochondrial DNA and mitochondrial dysfunction are now emerging as important factors in the etiology of neuropsychiatric disorders $[15,16]$. However, few studies have focused on low-dose MeHg-induced alternations in mitochondrial mtDNA and the investigation of the underlying mechanisms involved in low-dose $\mathrm{MeHg}$-induced toxicity is required.

In the present study, we evaluated the effect of low-dose $\mathrm{MeHg}$ on human neural progenitor cells (hNPCs). We analyzed the effect of $\mathrm{MeHg}$ on cell viability and cell apoptosis by treating the ReNcell CX cell, an hNPCs line, with low concentrations of $\mathrm{MeHg}(\leq 50 \mathrm{nM})$. Because the toxic effects of $\mathrm{MeHg}$ are mainly due to a sustained redox-cycling effect, which result in oxidative stress-related insults, we focused primarily on the examination of ROS production and mitochondria function. Moreover, we investigated mitochondrial gene expression and mtDNA damage in MeHg-treated hNPCs. Our findings suggest that low-dose $\mathrm{MeHg}$ induced toxicity in hNPCs through altering mitochondrial function and inducing oxidative damage to mtDNA.

\section{Material and Methods}

2.1. Cell Culture. Immortalized human neural progenitor cells (ReNcell CX cells) were obtained commercially from Millipore (Temecula, CA). Cells (frozen at passage two) were recovered and cultured on a $100 \mathrm{~mm}$ diameter dish (Corning, Inc., Corning, NY) precoated with laminin, using ReNcell NSC Maintenance Medium containing fresh EGF $(20 \mathrm{ng} / \mathrm{mL}$; Millipore) and FGF-2 (20 ng/mL; Millipore), as described previously [17].

2.2. $\mathrm{MeHg}$ Treatment. MeHg was dissolved in DMSO. The hNPCs were seeded at a density of $2.5 \times 10^{4} /$ well in laminincoated 96-well plates. After $24 \mathrm{~h}$ incubation, the medium was changed and $\mathrm{MeHg}(0 \mathrm{nM}, 10 \mathrm{nM}$, and $50 \mathrm{nM})$ was added followed by another $24 \mathrm{~h}$ culture. All experiments were performed in triplicates and repeated at least three times.

2.3. Assessment of Mitochondrial Metabolic Function. Mitochondrial metabolic function of hNPCs was determined with the dye methylthiazoletetrazolium (MTT) to formazan [18]. After being treated with MeHg for $20 \mathrm{~h}, 10 \mu \mathrm{L}$ MTT solutions were added to each well, followed by incubation for $4 \mathrm{~h}$ at $37^{\circ} \mathrm{C}$. The optical density (OD) was detected using a microplate reader (Biotek, Synergy HT, USA) at a test wavelength of $490 \mathrm{~nm}$.

2.4. Analysis of Apoptosis by Flow Cytometry. MeHg-induced apoptosis was detected using Alexa Fluor ${ }^{\circledR} 488$ Annexin V/Dead Cell Apoptosis Kit (Life technology), according to the manufacturer's protocol. Briefly, $1 \times 10^{6}$ dissociated cells were washed twice in cold PBS and resuspended in $1 \mathrm{x}$ binding buffer. Then the cells were stained with $5 \mu \mathrm{L}$ Annexin V-FITC and $1 \mu \mathrm{L}$ PI for $15 \mathrm{~min}$ in the dark, followed by flow cytometric analysis (Epics Altra, Beckman Coulter, USA).

2.5. Measurement of Reactive Oxygen Species (ROS). Intracellular ROS production was measured using DCF-DA (Molecular Probes, Beyotime, Jiangsu, China) [17]. The hNPCs were grown to $80 \%$ confluence in $3 \mathrm{~cm}$ laminin-coated culture dish and treated with $\mathrm{MeHg}(10 \mathrm{nM}$ and $50 \mathrm{nM})$ for $24 \mathrm{~h}$. The positive control groups were treated with Rosup for $30 \mathrm{~min}$ at $37^{\circ} \mathrm{C}$ in the dark place. Then the hNPCs were incubated with $100 \mu \mathrm{L}$ of $1 \mathrm{x}$ DCFH-DA/media solution and placed at $37^{\circ} \mathrm{C}$ for $30 \mathrm{~min}$. Images were captured using the Olympus microscope system. Fluorescence intensity values were reported as the percentage increase of intracellular ROS with respect to control.

2.6. Quantitative Real Time PCR. Total cellular RNA was isolated using Trizol reagent (Invitrogen) according to the manufacturer's recommendations, followed by a reverse transcription with cDNA synthesis kit (Thermo). cDNA was synthesized from $2 \mu \mathrm{g}$ of total RNA using $1 \mu \mathrm{L}$ of reverse transcriptase and $50 \mathrm{ng} / \mathrm{mL}$ oligo (dT). Each qPCR was carried out in triplicate using SYBR Green PCR Master Mix (Applied Biosystems, CA, USA) at one cycle of $95^{\circ} \mathrm{C}$ for $10 \mathrm{~min}, 40$ cycles of $95^{\circ} \mathrm{C}$ for $15 \mathrm{~s}$, and $60^{\circ} \mathrm{C}$ for $1 \mathrm{~min}$ on ABI Stepone Plus Real Time PCR Detection System (Applied Biosystems). PCR mix included $1 \mu \mathrm{L}$ template cDNA, $5 \mu \mathrm{L}$ SYBR Green PCR Master Mix (Applied Biosystems), $3 \mu \mathrm{L}$ $\mathrm{ddH}_{2} \mathrm{O}, 1 \mu \mathrm{L}(200 \mathrm{nM})$ of forward and reverse primers mix. Fold changes in the expression of each gene were calculated by a comparative threshold cycle $(\mathrm{Ct})$ method using the formula $2^{-(\Delta \Delta C t)}$. PCR primer sequences are available in Table 1.

2.7. Detection of Mitochondrial Membrane Potential. Mitochondrial membrane potential was measured using JC1 Mitochondrial Membrane Potential Detection Kit (Beyotime) according to the manufacturer's protocol. Mitochondrial membrane potential was measured using a fluorescence microplate reader (Biotek, Synergy HT, USA), and images were captured using the Olympus microscope system. Jaggregates are detected as red fluorescence and J-monomers are detected as green fluorescence. The mitochondriondirected fluorescence-sensitive probe JC-1 was used to determine variations in mitochondrial membrane potential 
TABLE 1: PCR primer sequences.

\begin{tabular}{lll}
\hline Primer name & Forward & Reverse \\
\hline ND1 & ACCCCCTAGGAATCACCTCC & GCCTAGGAGGTCTGGTGAGA \\
Cytb & CGATTCCGCTACGACCAACT & AGGTTTGAGGGGGAATGCTG \\
ATP6 & CTGTTCGCTTCATTCATTGC & AGTCATTGTTGGGTGGTGATT \\
GAPDH & GTCTCCTCTGACTTCAACAGCG & ACCACCCTGTTGCTGTAGCCAA \\
\hline
\end{tabular}

$(\Delta \psi \mathrm{m})$. Briefly, hNPCs $\left(1 \times 10^{5}\right.$ per well of a 96 -well plate $)$ were preloaded with JC-1 $(2 \mathrm{mg} / \mathrm{mL})$ and stimulated with $10 \mu \mathrm{M}$ CCCP as a positive control at $37^{\circ} \mathrm{C}$ for $20 \mathrm{~min}$. Each experiment was determined in triplicate, and results are expressed as means \pm SEM.

2.8. Determination of ATP Content. The intracellular ATP concentration was determined with an ATP determination kit (Life Technologies) following the manufacturer's instruction. A $10 \mu \mathrm{L}$ sample or $10 \mu \mathrm{L}$ ATP standard solutions were added to $90 \mu \mathrm{L}$ of reaction buffer in a 96-well plate. Each reaction contained $1.25 \mu \mathrm{g} / \mathrm{mL}$ of firefly luciferase, $50 \mu \mathrm{M}$ D-luciferin, and $1 \mathrm{mM}$ DTT in $1 \mathrm{x}$ reaction buffer. After 15-minute incubation, luminescence was measured using a microplate reader (Biotek, Synergy HT, USA). All experiments were run in triplicate, and the background luminescence was subtracted from the measurement. ATP concentrations in experimental samples were calculated from the ATP standard curve. For protein quantification, a colorimetric method (Pierce bicinchoninic acid [BCA] protein assay kit) was carried out according to the manufacturer's instructions.

2.9. Analysis of mtDNA Mutations. Total DNA was extracted from cell samples. Mutations in mitochondrial DNA were determined by PCR, cloning, and sequencing, using primers that specifically amplified the NADH dehydrogenase subunit 1 gene (nucleotide position 3307-4262), ATP synthase 6 gene (nucleotide position 8527-9207), cytochrome b gene (nucleotide position 14747-15887), and noncoding control region (nucleotide position 16024-576) of ReNcell CX mtDNA.

2.10. Statistical Analysis. Statistical analysis was performed using Stata 10.0 statistic program. Data are shown as mean \pm SEM. Multiple group comparisons were carried out by one-way analysis of variance (one-way ANOVA), followed by Bonferroni's post hoc test. A $P<0.05$ was considered statistically significant.

\section{Results}

3.1. MeHg Decreased Mitochondrial Function and Induced Apoptosis in hNPCs. The conversion of methylthiazoletetrazolium to formazan can indicate mitochondrial function and cell viability. The hNPCs were exposed to $\mathrm{MeHg}$ at concentrations of $0 \mathrm{nM}, 10 \mathrm{nM}$, and $50 \mathrm{nM}$ for 24 hours. We found that $\mathrm{MeHg}$ decreased mitochondrial metabolic function and cell viability in hNPCs in a concentrationdependent manner (Figure 1). At $50 \mathrm{nM} \mathrm{MeHg}$, tetrazolium

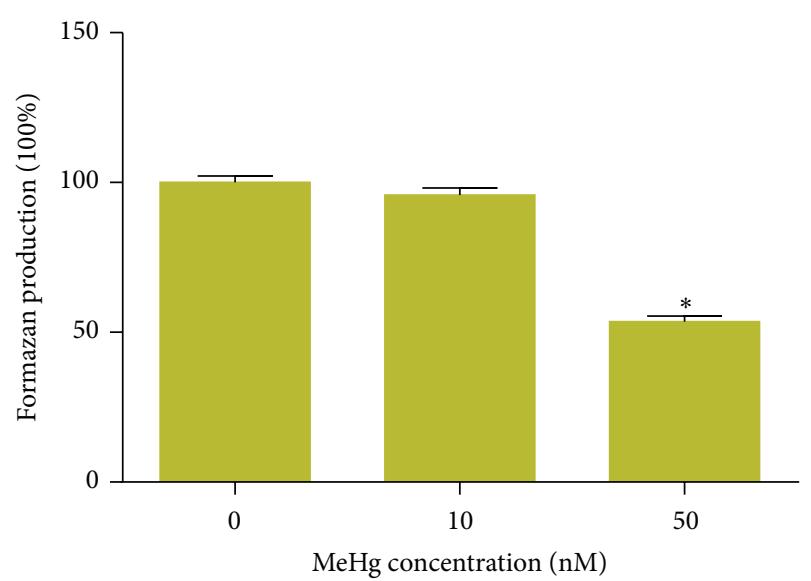

Figure 1: MeHg decreases mitochondrial metabolic function in hNPCs. The results are given as percentage of controls (set to 100\%). All experiments were repeated three times (technical triplicates) with biological triplicates $(n=3)$. Bar graphs show mean \pm SEM $\left({ }^{*} P<0.05\right)$.

salt conversion to formazan was reduced to $46.5 \%$ of the control value.

To examine whether MeHg-induced cytotoxicity involves apoptosis, we performed flow cytometric analysis of $\mathrm{MeHg}$ treated ReNcell CX cells by Annexin V-FITC binding assay and PI staining. As shown in Figure 2, Annexin V-PI staining assays detected significantly increased Annexin $\mathrm{V}$-positive apoptotic cells in $50 \mathrm{nM}$ MeHg-treated hNPCs than the control group ( $0 \mathrm{nM}$ : $3.64 \pm 0.49 ; 10 \mathrm{nM}$ : $4.31 \pm 0.29 ; 50 \mathrm{nM}$ : $13.90 \pm 5.47$ ) (Figures 2(a) and 2(b)).

3.2. Effect of $\mathrm{MeHg}$ on ROS Generation in hNPCs. Accumulating evidence has revealed that ROS are important for the induction of apoptosis. Oxidative stress in particular is considered to be one of the main mechanisms related to MeHg-induced neurotoxicity both in vivo and in vitro [19]. In this study, the effect of MeHg on the generation of ROS in hNPCs was measured by the DCFH-DA assay (Figure 3(a)). Fluorescence microscope images showed that fluorescence signal of DCF-DA (green) was increased significantly after MeHg treatments $(10 \mathrm{nM}, 1.47 \pm 0.05 ; 50 \mathrm{nM}, 1.69 \pm 0.06)$ (Figure 3(b)).

3.3. MeHg Alters Mitochondrial mRNA Transcripts and Mitochondrial Functions in hNPCs. To investigate whether MeHg can change mitochondrial proliferation, we examined the mRNA expression of several genes involved in mtDNA 

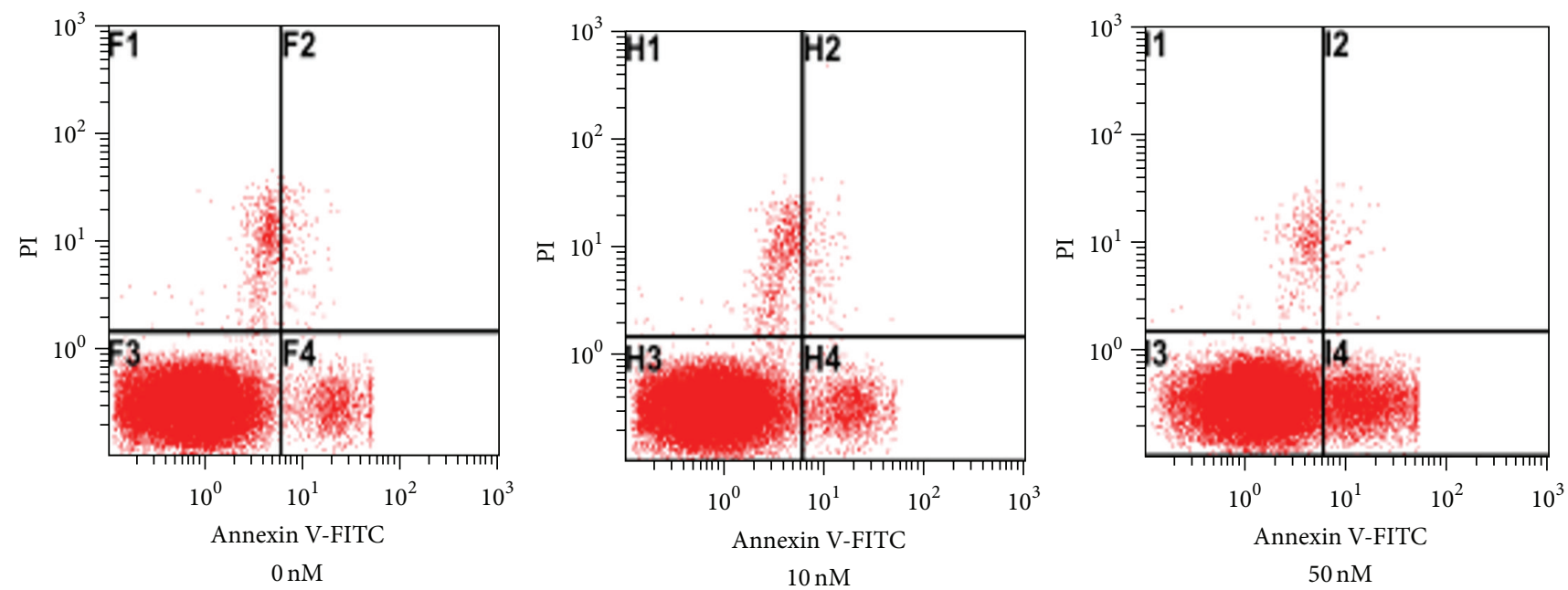

(a)

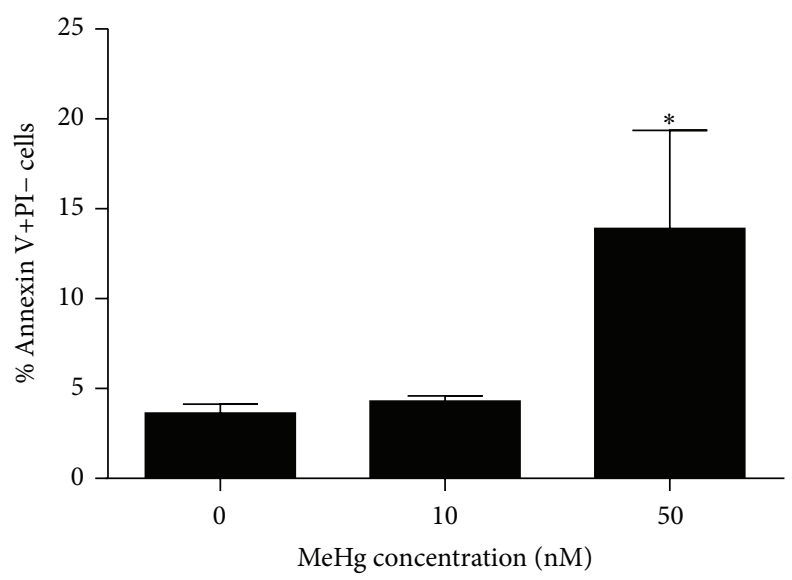

(b)

FIGURE 2: MeHg-induced apoptosis in hNPCs. (a) Cells were stained with Annexin V and PI. Dot plots showed representative staining by flow cytometry, showing the existence of 4 cellular populations: AnnV-/PI-, AnnV+/PI-, AnnV-/PI+, and AnnV+/PI+ (\% of each population for all three conditions is provided). (b) The degree ofapoptosis was shown as (or calculated by) the percentage of Annexin V-positive cells in cells treated with $\mathrm{MeHg}$. All experiments were repeated three times (technical triplicates) with biological triplicates $(n=3)$. Bar graphs show mean $\pm \operatorname{SEM}\left({ }^{*} P<0.05\right)$.

biogenesis and found that $\mathrm{MeHg}$ significantly increased the expression of ND1 (fold change: $10 \mathrm{nM}, 3.28 \pm 0.30 ; 50 \mathrm{nM}$, $4.31 \pm 0.26$ ), Cytb (fold change: $10 \mathrm{nM}, 2.08 \pm 0.09 ; 50 \mathrm{nM}$, $2.53 \pm 0.31$ ), and ATP6 (fold change: $10 \mathrm{nM}, 1.88 \pm 0.33 ; 50 \mathrm{nM}$, $6.03 \pm 0.18)$ (Figure 4$)$.

Moreover, to examine the underlying changes of mitochondrial function induced by $\mathrm{MeHg}$, we then assessed mitochondrial membrane potential $(\Delta \psi \mathrm{m})$ and ATP cellular content as indicators of mitochondrial function in hNPCs. As compared with untreated cells, $\mathrm{MeHg}$-treated cells revealed a reduced JC-1 aggregation (shift from red/orange fluorescence to green fluorescence), an observation that reflected a drop in $\Delta \psi \mathrm{m}$ (Figures 5(a) and 5(b)). Surprisingly, uncoupled with the increase in expressions of respiratory genes, Figure 6 revealed a dose-dependent loss in ATP content and a significant reduction was observed in $50 \mathrm{nM}$ MeHg-treated cells (0 nM, $4.42 \pm 1.13 ; 10 \mathrm{nM}, 2.40 \pm 0.74 ; 50 \mathrm{nM}, 0.66 \pm 0.10$ ).
3.4. MeHg Induced the mtDNA Mutation. We observed that $\mathrm{MeHg}$ increased the number of specific point mutations of DLoop of mtDNA ( $0 \mathrm{nM}, 9 ; 10 \mathrm{nM}, 18 ; 50 \mathrm{nM}, 23)$, ND1 gene (0 nM, 6; $10 \mathrm{nM}, 6 ; 50 \mathrm{nM}, 16)$, Cytb gene (0 nM, 2; $10 \mathrm{nM}$, $4 ; 50 \mathrm{nM}, 5)$, and ATP6 gene ( $0 \mathrm{nM}, 0 ; 10 \mathrm{nM}, 2 ; 50 \mathrm{nM}, 2)$. The prevalence of the mtDNA mutations found previously unreported in http://www.mitomap.org/ was summarized in Tables $2-5$. The data were confirmed by an independent PCR and sequencing analysis, which demonstrated the difference between each group.

\section{Discussion}

In this study, we demonstrated that exposure to low-dose $\mathrm{MeHg}$ significantly increased ROS production, reduced mitochondrial metabolic function, inhibited cell viability, and 


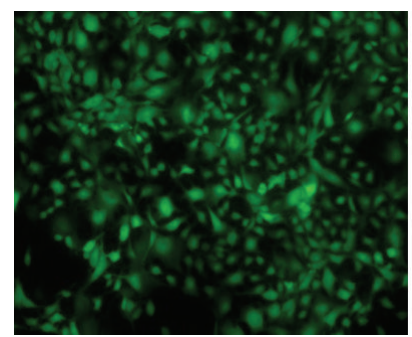

Positive control

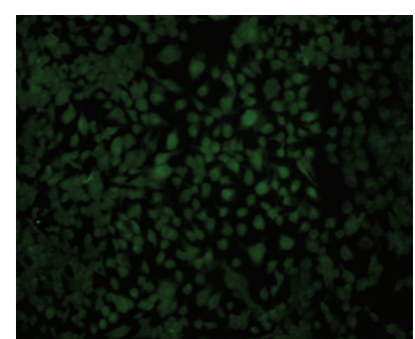

$0 \mathrm{nM}$

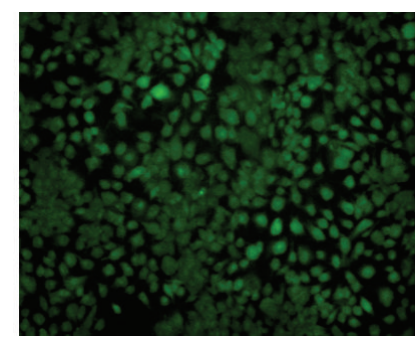

$10 \mathrm{nM}$

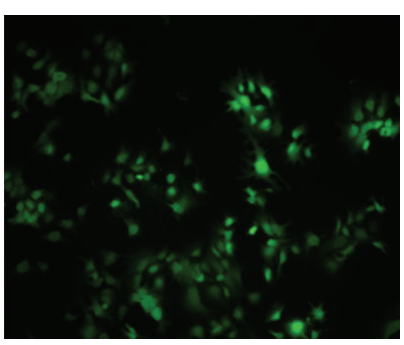

$50 \mathrm{nM}$

(a)

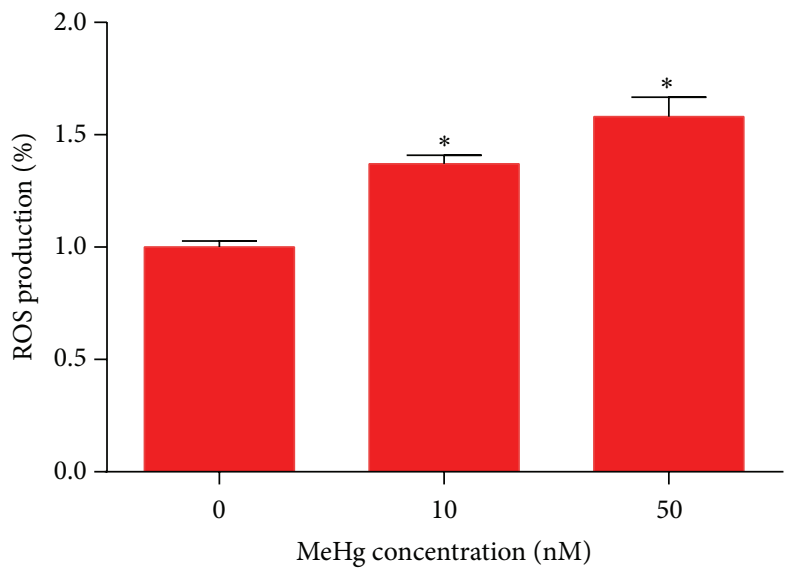

(b)

Figure 3: Effect of MeHg on the production of ROS in hNPCs. (a) Cells were treated with $0 \mathrm{nM}, 10 \mathrm{nM}$, and $50 \mathrm{nM} \mathrm{MeHg}$, and the level of ROS was measured by fluorescence microscopic images of DCF-DA signal. (b) The relative ROS levels were presented as fold differences based on control. Results are expressed as means \pm SEM $(n=3) .{ }^{*} P<0.05$ when compared with the corresponding control group (dose: $0 \mathrm{nM})$.

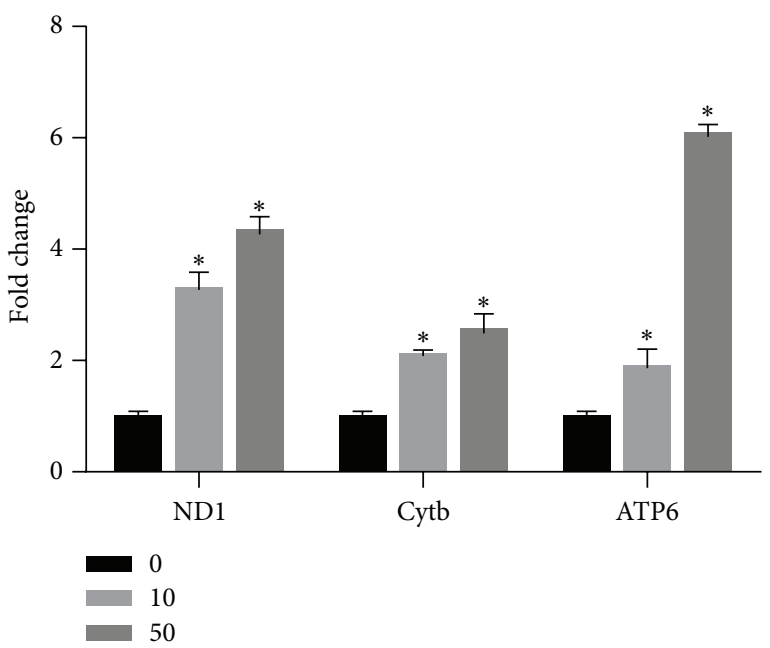

Figure 4: qPCR analysis of ND1, Cytb, and ATP6 mRNA expression levels performed on RNA extracted from hNPCs treated with $0 \mathrm{nM}$, $10 \mathrm{nM}$, and $50 \mathrm{nM} \mathrm{MeHg}$. The relative mRNA levels were presented as fold differences based on control. Results are expressed as means $\pm \operatorname{SEM}(n=3) .{ }^{*} P<0.05$ when compared with the corresponding control group (dose: $0 \mathrm{nM}$ ). induced apoptosis in hNPCs. In addition, we found a significant loss in $\Delta \psi \mathrm{m}$ and a dramatic decrease in ATP levels after $\mathrm{MeHg}$ treatments. Interestingly, $\mathrm{MeHg}$-induced mitochondrial dysfunction could not be rescued by elevated mitochondrial biogenesis, since we observed significant increase of ND1, Cytb, and ATP6 mRNA expression in response to low-dose $\mathrm{MeHg}$ exposure. Finally, we first detected that the number of mtDNA (ND1, Cytb, ATP6, and D-Loop) mutations was significantly higher in the $50 \mathrm{nM} \mathrm{MeHg}-$ treated group in hNPCs.

The mitochondrion has been recognized as a critical target of $\mathrm{MeHg}$ toxicity and a major source of constitutive cellular ROS. Existing evidence supports the role of mitochondrial-mediated oxidative stress to $\mathrm{MeHg}$ neurotoxicity, but the majority of investigations have been performed in mature neural cells [20, 21], and the potential role of $\mathrm{MeHg}$ induced ROS in hNPCs is poorly understood. Consistently, we observed a significant increase in ROS generation following $\mathrm{MeHg}$ exposure in hNPCs (Figure 3). The ROS could be produced after exposure to lower concentration of $\mathrm{MeHg}$ $(10 \mathrm{nM})$ in hNPCs than in neurons $(1.5 \mu \mathrm{M})$ [22]. Therefore, the high ROS levels observed after $\mathrm{MeHg}$ exposure in the present study further support the hypothesis that exposure 



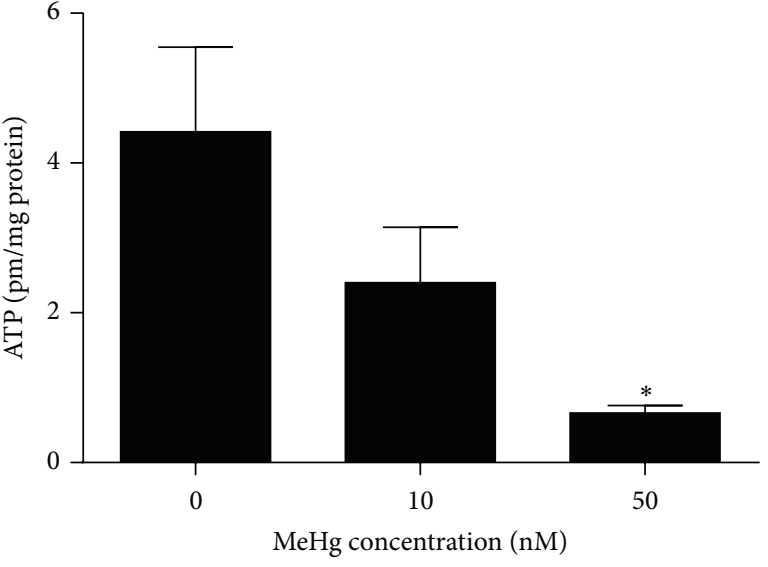

Figure 6: ATP levels were measured in freshly prepared cell extracts treated with various concentrations of $\mathrm{MeHg}$ using the ATP determination kit. Results are expressed as means \pm SEM $(n=3)$. ${ }^{*} P<0.05$ when compared with the corresponding control group (dose: $0 \mathrm{nM}$ ).

to low-dose MeHg leads to toxicity in hNPCs. Furthermore, these findings are in agreement with results of several previous in vivo and in vitro studies from whole brain [2325]. Thus, the agreement between previous publications and our present findings, gathered in a diversity of preparations, further confirms the use of hNPCs in examining the toxicity following exposure to $\mathrm{MeHg}$.

Mitochondria are maternally inherited and have a primary function of generating ATP via oxidative phosphorylation. Additionally, mitochondria are vital role in the regulation of complex survival signals that determine whether cells live or die and are closely involved in several other functions including cellular differentiation, growth, and cell cycle control [26]. It has been shown that MeHg-induced ROS production occurs with reduced mitochondrial function [27]. In the present study, we observed that $\mathrm{MeHg}$ exposure impaired mitochondrial function in hNPCs, demonstrated by a significant loss in $\Delta \psi \mathrm{m}$ at $10 \mathrm{nM} \mathrm{MeHg}$-treated group. Furthermore, we found that ATP levels were dramatically decreased after $\mathrm{MeHg}$ exposure, which are consistent with previous studies [27]. Moreover, mitochondria dysfunction was further confirmed by the observation that $\mathrm{MeHg}$ treatment significantly reduced the conversion of methylthiazoletetrazolium to formazan (Figure 1). This reaction is mainly catalyzed by succinate dehydrogenase in the mitochondria, although other dehydrogenases can also contribute. Collectively, the findings presented here suggest that $\mathrm{MeHg}$ exposure, at the concentration as low as $10 \mathrm{nM}$, impairs mitochondrial function and lowers cell viability. Meanwhile, we found that $24 \mathrm{~h}$ exposure to low doses of $\mathrm{MeHg}$, varied from $10 \mathrm{nM}$ to $50 \mathrm{nM}$, induced apoptosis of cultured hNPCs. Importantly, these doses of $\mathrm{MeHg}$ mimic the environmental exposure and are even below the doses in human cord blood [28]. Since the available evidence from in vivo and in vitro studies shows that MeHg-induced apoptosis is mediated through the mitochondrial-dependent pathway in neural developmental toxicity [29], the present findings suggest that
TABLE 2: Specific point mutations of ND1 gene found after treatment with MeHg in hNPCs.

\begin{tabular}{|c|c|c|}
\hline Group & Gene site & Mutation type \\
\hline \multirow{6}{*}{$0 \mathrm{nmol} / \mathrm{L}$} & 3450 & $\operatorname{del}(\mathrm{C})$ \\
\hline & 3487 & $\mathrm{C} \rightarrow \mathrm{G}$ \\
\hline & 3653 & $\mathrm{~T} \rightarrow \mathrm{C}$ \\
\hline & 3728 & $\mathrm{~A} \rightarrow \mathrm{G}$ \\
\hline & 4018 & $A \rightarrow G$ \\
\hline & 4219 & $\mathrm{~T} \rightarrow \mathrm{C}$ \\
\hline \multirow{6}{*}{$10 \mathrm{nmol} / \mathrm{L}$} & 3319 & $A \rightarrow C$ \\
\hline & 3321 & $\mathrm{C} \rightarrow \mathrm{A}$ \\
\hline & 3323 & $\mathrm{~T} \rightarrow \mathrm{C}$ \\
\hline & 3415 & $\mathrm{C} \rightarrow \mathrm{A}$ \\
\hline & 3704 & $\mathrm{~T} \rightarrow \mathrm{C}$ \\
\hline & 3791 & $\mathrm{~T} \rightarrow \mathrm{C}$ \\
\hline \multirow{15}{*}{$50 \mathrm{nmol} / \mathrm{L}$} & 3316 & $\operatorname{del}(G)$ \\
\hline & 3346 & $\mathrm{C} \rightarrow \mathrm{G}$ \\
\hline & 3376 & $\mathrm{G} \rightarrow \mathrm{A}$ \\
\hline & 3471 & $\mathrm{C} \rightarrow \mathrm{T}$ \\
\hline & 3495 & $\mathrm{C} \rightarrow \mathrm{T}$ \\
\hline & 3497 & $\mathrm{C} \rightarrow \mathrm{G}$ \\
\hline & 3501 & $\mathrm{~A} \rightarrow \mathrm{C}$ \\
\hline & $3510: 3511$ & ins (AT) \\
\hline & $3547: 3548$ & ins (AT) \\
\hline & 3556 & $\mathrm{C} \rightarrow \mathrm{T}$ \\
\hline & $3557: 3558$ & ins $(\mathrm{T})$ \\
\hline & $3562: 3563$ & ins (AT) \\
\hline & 3579 & $\operatorname{del}(\mathrm{A})$ \\
\hline & 4043 & $\mathrm{G} \rightarrow \mathrm{A}$ \\
\hline & 4103 & $\mathrm{~T} \rightarrow \mathrm{C}$ \\
\hline
\end{tabular}

TABLE 3: Specific point mutations of Cytb gene found after treatment with $\mathrm{MeHg}$ in hNPCs.

\begin{tabular}{lcc}
\hline Group & Gene site & Mutation type \\
\hline $0 \mathrm{nmol} / \mathrm{L}$ & 15611 & $\mathrm{~T} \rightarrow \mathrm{C}$ \\
& 15719 & $\mathrm{~T} \rightarrow \mathrm{A}$ \\
\hline \multirow{3}{*}{$10 \mathrm{nmol} / \mathrm{L}$} & 15017 & $\mathrm{~T} \rightarrow \mathrm{C}$ \\
& 15251 & $\mathrm{~T} \rightarrow \mathrm{C}$ \\
& 15682 & $\operatorname{del}(\mathrm{A})$ \\
& 15740 & $\operatorname{del}(\mathrm{CT})$ \\
\hline \multirow{2}{*}{$50 \mathrm{nmol} / \mathrm{L}$} & 15082 & $\mathrm{C} \rightarrow \mathrm{G}$ \\
& 15621 & $\mathrm{~T} \rightarrow \mathrm{C}$ \\
& 15679 & $\operatorname{del}(\mathrm{A})$ \\
& 15702 & $\operatorname{del}(\mathrm{C})$ \\
& 15743 & $\operatorname{del}(\mathrm{C})$ \\
\hline
\end{tabular}

mitochondria are the primary target for $\mathrm{MeHg}$ and that ROS production could be a consequence of damage to the mitochondria rather than being an initiator of mitochondrial damage.

It has been widely reported that alterations in intracellular ROS level are often associated with changes in 
TABLE 4: Specific point mutations of ATP6 gene found after treatment with MeHg in hNPCs.

\begin{tabular}{lcc}
\hline Group & Gene site & Mutation type \\
\hline \multirow{2}{*}{$10 \mathrm{nmol} / \mathrm{L}$} & 8636 & $\mathrm{~T} \rightarrow \mathrm{G}$ \\
& 9048 & $\mathrm{~T} \rightarrow \mathrm{G}$ \\
\hline \multirow{2}{*}{$50 \mathrm{nmol} / \mathrm{L}$} & 9056 & $\mathrm{C} \rightarrow \mathrm{T}$ \\
& 9166 & $\mathrm{~T} \rightarrow \mathrm{C}$ \\
\hline
\end{tabular}

TABLE 5: Specific point mutations of D-Loop gene found after treatment with $\mathrm{MeHg}$ in hNPCs.

\begin{tabular}{|c|c|c|}
\hline Group & Gene site & Mutation type \\
\hline \multirow{5}{*}{$0 \mathrm{nmol} / \mathrm{L}$} & $349: 350$ & ins $(C)$ \\
\hline & 378 & $\operatorname{del}(\mathrm{A})$ \\
\hline & $382: 383$ & ins $(C)$ \\
\hline & 387 & $\operatorname{del}(C)$ \\
\hline & $444: 445$ & ins (A) \\
\hline \multirow{11}{*}{$10 \mathrm{nmol} / \mathrm{L}$} & 302 & $A \rightarrow G$ \\
\hline & $353: 354$ & $\operatorname{del}(\mathrm{CC})$ \\
\hline & $372: 373$ & $\operatorname{del}(\mathrm{TA})$ \\
\hline & 378 & $\operatorname{del}(C)$ \\
\hline & 385 & $\operatorname{del}(A)$ \\
\hline & 403 & ins $(\mathrm{T})$ \\
\hline & 410 & $\mathrm{G} \rightarrow \mathrm{C}$ \\
\hline & 413 & $\mathrm{G} \rightarrow \mathrm{T}$ \\
\hline & 493 & $\mathrm{~A} \rightarrow \mathrm{C}$ \\
\hline & 505 & $\operatorname{del}(C)$ \\
\hline & 16125 & $\mathrm{G} \rightarrow \mathrm{A}$ \\
\hline \multirow{15}{*}{$50 \mathrm{nmol} / \mathrm{L}$} & 123 & $A \rightarrow G$ \\
\hline & $246: 247$ & ins (TG) \\
\hline & 324 & $\operatorname{del}(\mathrm{C})$ \\
\hline & 384 & $\operatorname{del}(\mathrm{A})$ \\
\hline & 394:395 & $\operatorname{del}(\mathrm{CA})$ \\
\hline & 397 & $\mathrm{~A} \rightarrow \mathrm{T}$ \\
\hline & $424: 425$ & $\operatorname{del}(\mathrm{TA})$ \\
\hline & 430 & $\mathrm{~T} \rightarrow \mathrm{A}$ \\
\hline & 440 & $\operatorname{del}(\mathrm{A})$ \\
\hline & 442 & $\mathrm{~T} \rightarrow \mathrm{C}$ \\
\hline & 457 & $\mathrm{G} \rightarrow \mathrm{C}$ \\
\hline & 469 & $\operatorname{del}(C)$ \\
\hline & 478 & $\operatorname{del}(A)$ \\
\hline & 490:491 & $\operatorname{del}(\mathrm{AC})$ \\
\hline & 493 & $\mathrm{~A} \rightarrow \mathrm{C}$ \\
\hline
\end{tabular}

mitochondrial abundance and the expression of respiratory genes [10]. Indeed, our results showed that low-dose $\mathrm{MeHg}$ increased mtDNA transcription in hNPCs, with increased mRNA expression of ND1, Cytb, and ATP6. Interestingly, we observed a decrease in ATP levels after MeHg exposure, indicating that the increased mitochondria biogenesis fails to compensate for the decline of mitochondrial respiratory function. The relationship between oxidative stress and mitochondria function is complicated. Oxidative stress-induced increase in mitochondrial abundance and expressions of respiratory genes may compensate for the decline of mitochondrial respiratory function. Simultaneously, ROS would also be generated from the increased mitochondria and thus cause much more oxidative damage to mitochondrial macromolecules, such as lipids and DNA, and consequently lead the cell to enter the process of senescence or apoptosis $[30,31]$.

Mitochondrial DNA is the critical importance for preserving mitochondrial respiratory function. Human mtDNA conserve a small genome, which is $16,569 \mathrm{bp}$ in length and encodes 13 polypeptides of ETC, 22 tRNAs, and 2 rRNAs located in the inner mitochondrial membrane (IMM) matrix [32]. It is noteworthy that mtDNA is highly susceptible to oxidative damage compared to nDNA, which is due to its close proximity to the cell's main source of ROS production, lack of a histone protection, and relatively less efficient DNA repair mechanisms [11]. Indeed, oxidative damage in mtDNA is a mutation rate that is 10 -fold greater as compared to nDNA [33]. Several studies have indicated the associations between genetic damage induced by $\mathrm{MeHg}$ and alterations of the cellular redox status, and it is conceivable that ROS induced DNA damage plays a role in the adverse health effects $[34,35]$. In the present study, we first observed that the number of mtDNA (ND1, Cytb, ATP6, and D-Loop) mutations was higher in the $50 \mathrm{nM} \mathrm{MeHg}$-treated group compared to the control, especially for mutations in ND1 and D-Loop in hNPCs (Tables 2-5). Meanwhile, we observed that low-dose MeHg increased mtDNA transcription with increased ROS in hNPCs. The increased copy number of mtDNA is suggested as a result of the feedback response that compensates for defective mitochondria bearing impaired respiratory chain or mutated mtDNA by ROS [36]. Conversely, an increase in expressions of respiratory genes could contribute to further oxidative stress leading to mtDNA instability, mitochondrial dysfunction, and oxidative damage [37]. Moderate oxidative stress may lead to the increase of mitochondrial abundance and mtDNA content [10]. Nevertheless, chronic exposure to oxidative stress may cause severe oxidative damage and agitate the stress response of the target cells [38]. Mitochondrial DNA damage may trigger cell deaths, which result from compromised bioenergetic function, genetic and protein instability, and increased ROS generation [39]. As expected, mtDNA instability can elicit mitochondrial dysfunction, including the loss in the mitochondrial membrane potential $(\Delta \psi \mathrm{m})$ and release of proapoptogenic agents, which drives disease formation, aging, and tumorigenesis [40]. Therefore, low-dose MeHg-induced long-term oxidative stress in mitochondria may be a contributory factor to the somatic mtDNA instability and thereby leads to a decline in mitochondrial respiratory function. Moreover, we have to point out that we do not directly detect ROS in mitochondria. In order to clear link between ROS generation and mitochondrial damage, further studies should be required.

In conclusion, our study provides evidence that low-dose $\mathrm{MeHg}$ exposure promotes mitochondrial gene upregulation in hNPCs, which, in turn, contributes to the respiratory chain generating more ROS. Excess ROS further damages mtDNA, leading to ATP depletion and membrane potential $(\Delta \psi \mathrm{m})$ loss. Ultimately, the additive or cooperative mechanisms 
of cellular disruptions caused by $\mathrm{MeHg}$ lead to cellular dysfunction and cell death.

\section{Competing Interests}

The authors declare that they have no competing interests.

\section{Acknowledgments}

Research was supported by Shanghai National Natural Science Funds (10ZR1401700). The authors thank Dr. Lin Jia of the University of Texas Southwestern Medical Center for helpful comments on this paper. Shanghai Projected "3-Year Action"(GWIV-27.3) was granted to the authors' department.

\section{References}

[1] M. Harada, "Minamata disease: methylmercury poisoning in Japan caused by environmental pollution," Critical Reviews in Toxicology, vol. 25, no. 1, pp. 1-24, 1995.

[2] T. W. Clarkson, L. Magos, and G. J. Myers, "The toxicology of mercury-current exposures and clinical manifestations," The New England Journal of Medicine, vol. 349, no. 18, pp. 1731-1737, 2003.

[3] M. Farina, M. Aschner, and J. B. T. Rocha, "Oxidative stress in MeHg-induced neurotoxicity," Toxicology and Applied Pharmacology, vol. 256, no. 3, pp. 405-417, 2011.

[4] P. Grandjean, P. Weihe, R. F. White et al., "Cognitive deficit in 7-year-old children with prenatal exposure to methylmercury," Neurotoxicology and Teratology, vol. 19, no. 6, pp. 417-428, 1997.

[5] E. M. Yokoo, J. G. Valente, L. Grattan, S. L. Schmidt, I. Platt, and E. K. Silbergeld, "Low level methylmercury exposure affects neuropsychological function in adults," Environmental Health: A Global Access Science Source, vol. 2, article 1, pp. 1-11, 2003.

[6] J. Stringari, A. K. C. Nunes, J. L. Franco et al., "Prenatal methylmercury exposure hampers glutathione antioxidant system ontogenesis and causes long-lasting oxidative stress in the mouse brain," Toxicology and Applied Pharmacology, vol. 227, no. 1, pp. 147-154, 2008.

[7] A. Spurgeon, "Prenatal methylmercury exposure and developmental outcomes: review of the evidence and discussion of future directions," Environmental Health Perspectives, vol. 114, no. 2, pp. 307-312, 2006.

[8] D. Roos, R. Seeger, R. Puntel, and N. Vargas Barbosa, "Role of calcium and mitochondria in MeHg-mediated cytotoxicity," Journal of Biomedicine and Biotechnology, vol. 2012, Article ID 248764, 15 pages, 2012.

[9] D. Joshi, M. D. Kumar, S. A. Kumar, and S. Sangeeta, "Reversal of methylmercury-induced oxidative stress, lipid peroxidation, and DNA damage by the treatment of $\mathrm{N}$-acetyl cysteine: a protective approach," Journal of Environmental Pathology, Toxicology and Oncology, vol. 33, no. 2, pp. 167-182, 2014.

[10] H.-C. Lee and Y.-H. Wei, "Mitochondrial biogenesis and mitochondrial DNA maintenance of mammalian cells under oxidative stress," International Journal of Biochemistry and Cell Biology, vol. 37, no. 4, pp. 822-834, 2005.

[11] F. M. Yakes and B. Van Houten, "Mitochondrial DNA damage is more extensive and persists longer than nuclear DNA damage in human cells following oxidative stress," Proceedings of the National Academy of Sciences of the United States of America, vol. 94, no. 2, pp. 514-519, 1997.
[12] N. M. Druzhyna, G. L. Wilson, and S. P. LeDoux, "Mitochondrial DNA repair in aging and disease," Mechanisms of Ageing and Development, vol. 129, no. 7-8, pp. 383-390, 2008.

[13] S. Ceccatelli, E. Daré, and M. Moors, "Methylmercury-induced neurotoxicity and apoptosis," Chemico-Biological Interactions, vol. 188, no. 2, pp. 301-308, 2010.

[14] C. Tamm, J. Duckworth, O. Hermanson, and S. Ceccatelli, "High susceptibility of neural stem cells to methylmercury toxicity: effects on cell survival and neuronal differentiation," Journal of Neurochemistry, vol. 97, no. 1, pp. 69-78, 2006.

[15] E. L. Streck, C. L. Gonçalves, C. B. Furlanetto, G. Scaini, F. DalPizzol, and J. Quevedo, "Mitochondria and the central nervous system: searching for a pathophysiological basis of psychiatric disorders," Revista Brasileira de Psiquiatria, vol. 36, no. 2, pp. 156-167, 2014.

[16] S. Ciccone, E. Maiani, G. Bellusci, M. Diederich, and S. Gonfloni, "Parkinson's disease: a complex interplay of mitochondrial DNA alterations and oxidative stress," International Journal of Molecular Sciences, vol. 14, no. 2, pp. 2388-2409, 2013.

[17] X. Chang, W. Lu, T. Dou et al., "Paraquat inhibits cell viability via enhanced oxidative stress and apoptosis in human neural progenitor cells," Chemico-Biological Interactions, vol. 206, no. 2, pp. 248-255, 2013.

[18] A. Dreiem and R. F. Seegal, "Methylmercury-induced changes in mitochondrial function in striatal synaptosomes are calciumdependent and ROS-independent," NeuroToxicology, vol. 28, no. 4, pp. 720-726, 2007.

[19] M. Farina, M. Aschner, and J. B. T. Rocha, "Oxidative stress in MeHg-induced neurotoxicity," Toxicology \& Applied Pharmacology, vol. 256, no. 3, pp. 405-417, 2011.

[20] J. L. Franco, T. Posser, P. R. Dunkley et al., "Methylmercury neurotoxicity is associated with inhibition of the antioxidant enzyme glutathione peroxidase," Free Radical Biology and Medicine, vol. 47, no. 4, pp. 449-457, 2009.

[21] P. Kaur, K. Schulz, M. Aschner, and T. Syversen, "Role of docosahexaenoic acid in modulating methylmercury-induced neurotoxicity," Toxicological Sciences, vol. 100, no. 2, pp. 423432, 2007.

[22] M. Polunas, A. Halladay, R. B. Tjalkens, M. A. Philbert, H. Lowndes, and K. Reuhl, "Role of oxidative stress and the mitochondrial permeability transition in methylmercury cytotoxicity," NeuroToxicology, vol. 32, no. 5, pp. 526-534, 2011.

[23] S. F. Ali, C. P. LeBel, and S. C. Bondy, "Reactive oxygen species formation as a biomarker of methylmercury and trimethyltin neurotoxicity," NeuroToxicology, vol. 13, no. 3, pp. 637-648, 1992.

[24] G. Shanker and M. Aschner, "Methylmercury-induced reactive oxygen species formation in neonatal cerebral astrocytic cultures is attenuated by antioxidants," Molecular Brain Research, vol. 110, no. 1, pp. 85-91, 2003.

[25] S. Yee and B. H. Choi, "Oxidative stress in neurotoxic effects of methylmercury poisoning," NeuroToxicology, vol. 17, no. 1, pp. 17-26, 1996.

[26] A. Trifunovic, A. Wredenberg, M. Falkenberg et al., "Premature ageing in mice expressing defective mitochondrial DNA polymerase," Nature, vol. 429, no. 6990, pp. 417-423, 2004.

[27] A. Dreiem, C. C. Gertz, and R. F. Seegal, "The effects of methylmercury on mitochondrial function and reactive oxygen species formation in rat striatal synaptosomes are agedependent," Toxicological Sciences, vol. 87, no. 1, pp. 156-162, 2005. 
[28] P. Grandjean, P. Weihe, R. F. White, and F. Debes, "Cognitive performance of children prenatally exposed to 'safe' levels of methylmercury," Environmental Research, vol. 77, no. 2, pp. 165$172,1998$.

[29] K. Sokolowski, A. Falluel-Morel, X. Zhou, and E. DiCiccoBloom, "Methylmercury (MeHg) elicits mitochondrialdependent apoptosis in developing hippocampus and acts at low exposures," NeuroToxicology, vol. 32, no. 5, pp. 535-544, 2011.

[30] C. Bladier, E. J. Wolvetang, P. Hutchinson, J. B. De Haan, and I. Kola, "Response of a primary human fibroblast cell line to $\mathrm{H}_{2} \mathrm{O}_{2}$ : senescence-like growth arrest or apoptosis?" Cell Growth and Differentiation, vol. 8, no. 5, pp. 589-598, 1997.

[31] Q. M. Chen, J. C. Bartholomew, J. Campisi, M. Acosta, J. D. Reagan, and B. N. Ames, "Molecular analysis of $\mathrm{H}_{2} \mathrm{O}_{2}$-induced senescent-like growth arrest in normal human fibroblasts: p53 and $\mathrm{Rb}$ control G1 arrest but not cell replication," Biochemical Journal, vol. 332, no. 1, pp. 43-50, 1998.

[32] S. Anderson, A. T. Bankier, B. G. Barrell et al., "Sequence and organization of the human mitochondrial genome," Nature, vol. 290, no. 5806, pp. 457-465, 1981.

[33] V. A. Bohr, T. Stevnsner, and N. C. de Souza-Pinto, "Mitochondrial DNA repair of oxidative damage in mammalian cells," Gene, vol. 286, no. 1, pp. 127-134, 2002.

[34] E. Y. Ben-Ozer, A. J. Rosenspire, M. J. McCabe Jr. et al., "Mercuric chloride damages cellular DNA by a non-apoptotic mechanism," Mutation Research/Genetic Toxicology and Environmental Mutagenesis, vol. 470, no. 1, pp. 19-27, 2000.

[35] G. R. M. Barcelos, D. Grotto, J. M. Serpeloni et al., "Protective properties of quercetin against DNA damage and oxidative stress induced by methylmercury in rats," Archives of Toxicology, vol. 85, no. 9, pp. 1151-1157, 2011.

[36] H.-C. Lee, P.-H. Yin, C.-Y. Lu, C.-W. Chi, and Y.-H. Wei, "Increase of mitochondria and mitochondrial DNA in response to oxidative stress in human cells," Biochemical Journal, vol. 348, part 2, pp. 425-432, 2000.

[37] A. Hiona and C. Leeuwenburgh, "The role of mitochondrial DNA mutations in aging and sarcopenia: implications for the mitochondrial vicious cycle theory of aging," Experimental Gerontology, vol. 43, no. 1, pp. 24-33, 2008.

[38] B. Uttara, A. V. Singh, P. Zamboni, and R. T. Mahajan, "Oxidative stress and neurodegenerative diseases: a review of upstream and downstream antioxidant therapeutic options," Current Neuropharmacology, vol. 7, no. 1, pp. 65-74, 2009.

[39] R.-M. Laberge, D. Adler, M. DeMaria et al., "Mitochondrial DNA damage induces apoptosis in senescent cells," Cell Death and Disease, vol. 4, no. 7, article e727, 2013.

[40] G. Kroemer, L. Galluzzi, and C. Brenner, "Mitochondrial membrane permeabilization in cell death," Physiological Reviews, vol. 87, no. 1, pp. 99-163, 2007. 


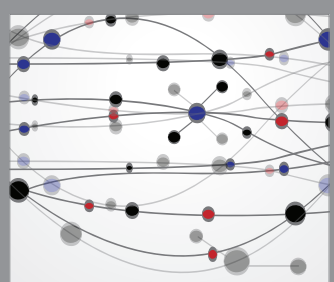

The Scientific World Journal
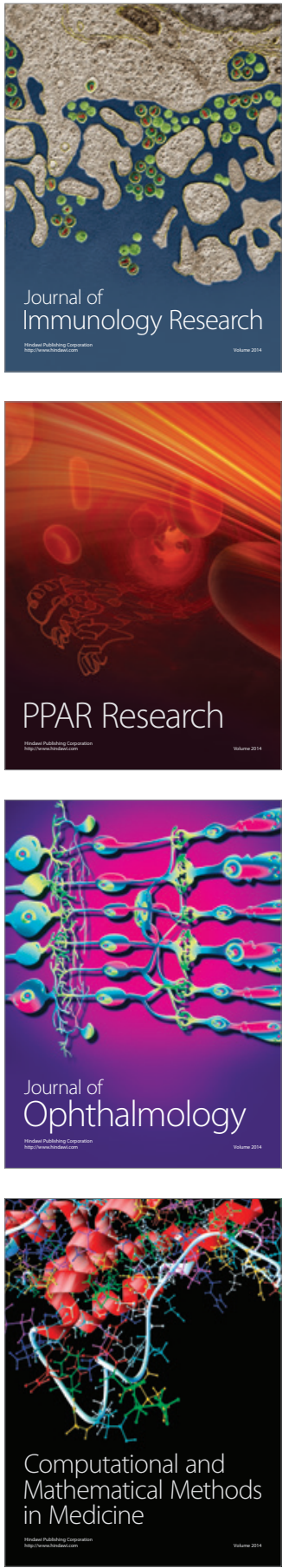

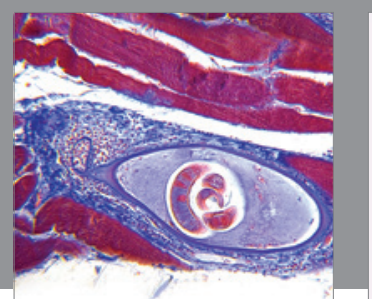

Gastroenterology Research and Practice

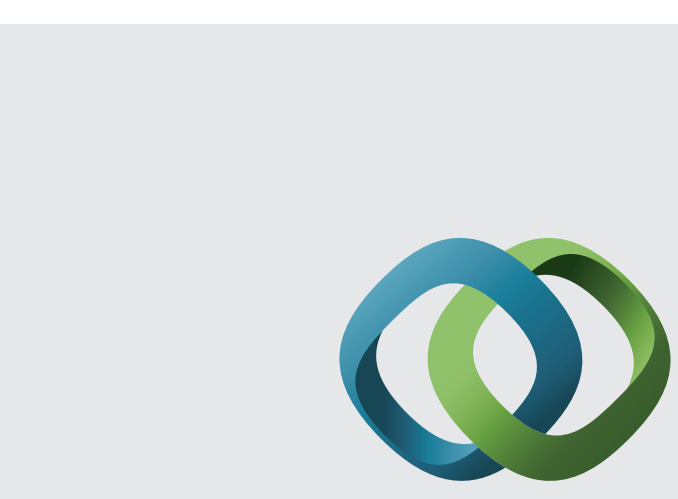

\section{Hindawi}

Submit your manuscripts at

http://www.hindawi.com
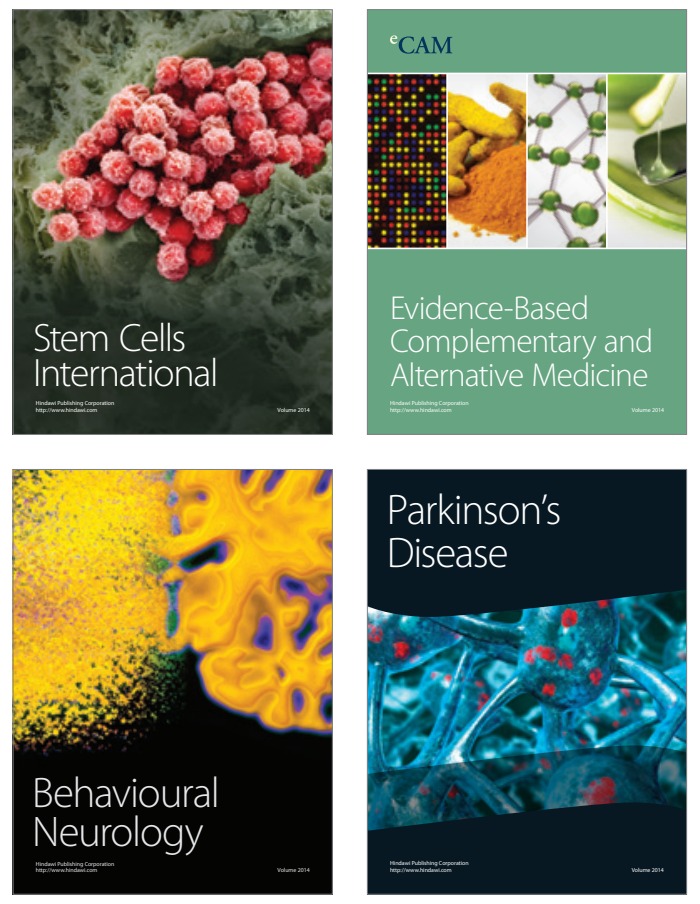
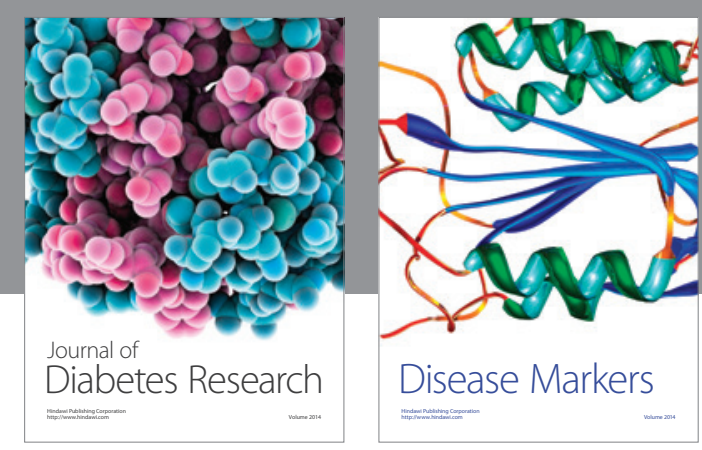

Disease Markers
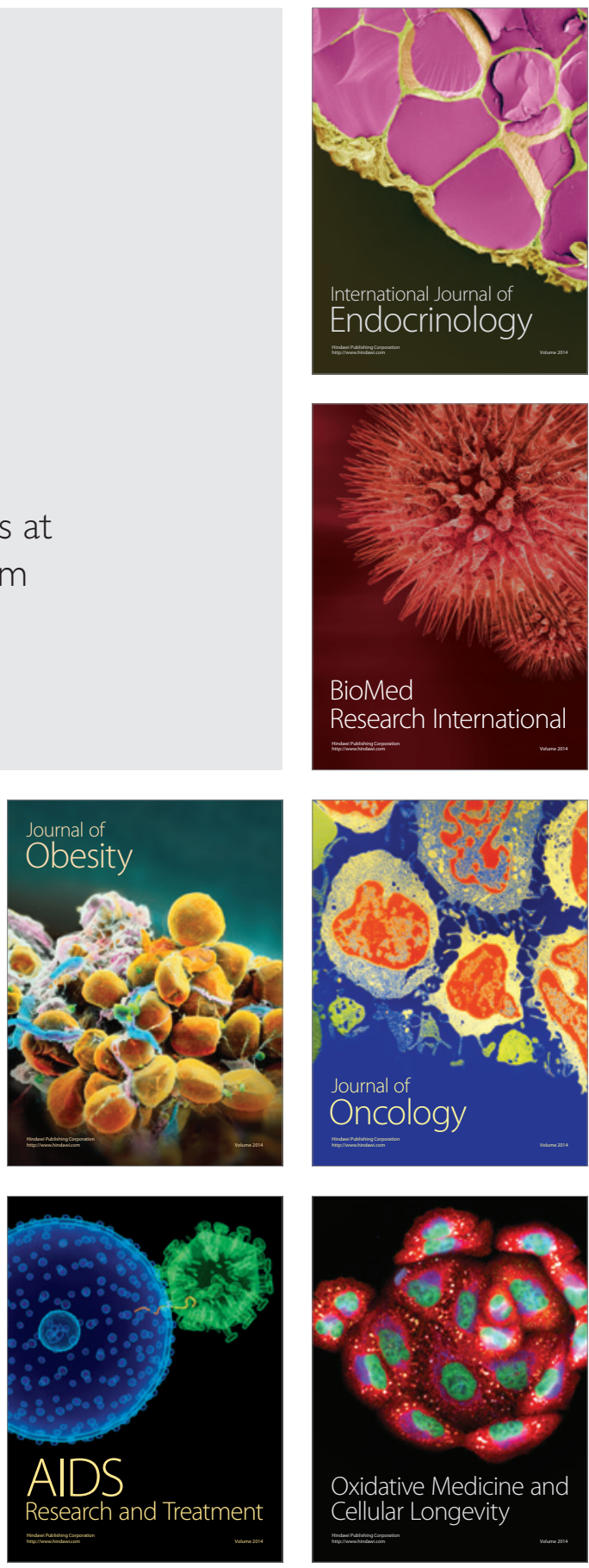